\title{
KEGIATAN KKN VIRTUAL MAHASISWI STIBA MAKASSAR BERBASIS AL-QUR'AN DI SUMATERA UTARA
}

\section{QUR'AN-BASED VIRTUAL KKN OF STIBA MAKASSAR STUDENTS IN NORTH SUMATERA}

\author{
Kurnaemi Anita \\ Sekolah Tinggi Ilmu Islam dan Bahasa Arab (STIBA) Makassar \\ Email: pustakaarabic@gmail.com
}

Nuraeni Novira

Sekolah Tinggi Ilmu Islam dan Bahasa Arab (STIBA) Makassar Email: nuraeni@stiba.ac.id

\begin{tabular}{|c|c|}
\hline Keywords : & ABSTRACT \\
\hline $\begin{array}{l}\text { North Sumatera, virtual KKN, } \\
\text { Quran, STIBA Makassar }\end{array}$ & $\begin{array}{l}\text { The purpose of the implementation of this KKN is to empower, foster, } \\
\text { and increase the capacity of the local community. The method of } \\
\text { implementing the KKN program begins by observing the condition } \\
\text { of the community using SOAR analysis which then produces several } \\
\text { programs including: (1) Seminar Al-Qur'an; (2) Tahfiz Harian; (3) } \\
\text { Pengajaran Al-Qur'an Metode Dirosa; (4) Taklim Fikih Muslimah, } \\
\text { dan (5) Poster Dakwah. All these programs are running well and } \\
\text { smoothly, this is characterized by the continued program of coaching } \\
\text { and teaching of the Qur'an even though the KKN has ended. As a } \\
\text { result, there appears to be a change in the attitudes and behavior of } \\
\text { more religious people, and the ability to read the Qur'an is getting } \\
\text { better. }\end{array}$ \\
\hline \multirow{2}{*}{$\begin{array}{l}\text { Kata kunci : } \\
\text { Sumatera Utara, KKN virtual, } \\
\text { Al-Qur'an, STIBA Makassar }\end{array}$} & ABSTRAK \\
\hline & $\begin{array}{l}\text { Tujuan pelaksanaan KKN ini adalah untuk memberdayakan, } \\
\text { membina, dan meningkatkan kapasitas masyarakat setempat. Metode } \\
\text { pelaksanaan program KKN diawali dengan melakukan pengamatan } \\
\text { kondisi masyarakat dengan menggunakan analisis SOAR yang } \\
\text { kemudian menghasilkan beberapa program di antaranya: (1) Seminar } \\
\text { Al-Qur'an; (2) Tahfiz Harian; (3) Pengajaran Al-Qur'an Metode } \\
\text { Dirosa; (4) Taklim Fikih Muslimah, dan (5) Poster Dakwah. Semua } \\
\text { program tersebut berjalan dengan baik dan lancar, hal ini ditandai } \\
\text { dengan berlanjutnya program pembinaan dan pengajaran Al-Qur'an } \\
\text { meskipun KKN telah berakhir. Walhasil, tampak perubahan sikap } \\
\text { dan perilaku masyarakat yang lebih religius, serta kemampuan } \\
\text { membaca Al-Qur'an mereka semakin baik. }\end{array}$ \\
\hline
\end{tabular}

Diterima: 16 Oktober 2021; Direvisi: 22 Desember 2021; Disetujui: 22 Desember 2021; Tersedia online: 31 Desember 2021

How to cite: Kurnaemi Anita, Nuraeni Novira, "Kegiatan KKN Virtual Mahasiswi STIBA Makassar Berbasis Al-Qur'an di Sumatera Utara", WAHATUL MUJTAMA': Jurnal Pengabdian Masyarakat Vol. 2, No. 2 (2021): 172-181. doi: 10.36701/wahatul.v2i2.439. 


\section{PENDAHULUAN}

Sumatera Utara (disingkat Sumut) adalah sebuah provinsi di Indonesia yang terletak di bagian utara Pulau Sumatera dengan ibukota provinsi di Kota Medan. Provinsi ini merupakan penggabungan dari tiga daerah administratif yang disebut keresidenan yaitu: Keresidenan Aceh, Keresidenan Sumatera Timur, dan Keresidenan Tapanuli. Dengan diterbitkannya Undang-Undang Republik Indonesia No. 10 Tahun 1948 pada tanggal 15 April 1948, maka ditetapkan bahwa Sumatera dibagi menjadi tiga provinsi yang masing-masing berhak mengatur dan mengurus rumah tangganya sendiri, yaitu Provinsi Sumatera Utara, Provinsi Sumatera Tengah, dan Provinsi Sumatera Selatan. Adapun pada tanggal 15 April 1948 selanjutnya ditetapkan sebagai hari jadi Provinsi Sumatera Utara ${ }^{1}$.

Secara geografis, Provinsi Sumatera Utara terletak pada $1^{\circ}-4^{\circ}$ Lintang Utara dan $98^{\circ}-100^{\circ}$ Bujur Timur, dengan batas wilayah di sebelah utara berbatasan dengan Provinsi Aceh dan Selat Malaka, sebelah selatan berbatasan dengan Provinsi Riau, Provinsi Sumatera Barat, dan Samudera Indonesia, sebelah barat berbatasan dengan Provinsi Aceh dan Samudera Indonesia, sebelah timur berbatasan dengan Selat Malaka. Sumatera Utara pada dasarnya dapat dibagi atas empat wilayah, yaitu Pesisir Timur, Pegunungan Bukit Barisan, Pesisir Barat dan Kepulauan Nias, serta terdapat 419 pulau di Provinsi Sumatera Utara. Pulau-pulau terluar adalah Pulau Simuk (Kepulauan Nias), dan Pulau Berhala di Selat Sumatera (Malaka). Kepulauan Nias terdiri dari Pulau Nias sebagai pulau utama dan pulau-pulau kecil lain di sekitarnya. Kepulauan Nias terletak di lepas pantai pesisir barat di Samudera Hindia, dan pusat pemerintahan terletak di Gunung Sitoli ${ }^{2}$.

Sumatera Utara merupakan provinsi yang dikenal memiliki banyak destinasi wisata, salah satunya yang telah dikenal dunia adalah Danau Toba yang memiliki keunikan geografi alam yang berbeda, selain wisata, perkebunan masih merupakan penyokong utama perekonomian provinsi ini dengan produk pertanian di antaranya: karet, cokelat, teh, kelapa sawit, kopi, cengkih, kelapa, kayu manis, dan tembakau, berbagai komoditi ini menyumbang devisa yang besar bagi Indonesia. Sumatera Utara juga dikenal sebagai penghasil komoditas holtikultura yang dihasilkan oleh Kabupaten Karo, Simalungun dan Tapanuli Utara dimana produk holtikultura tersebut telah diekspor ke Malaysia dan Singapura. Berdasarkan data Badan Pusat Statistik provinsi Sumatera Utara tahun $2021,{ }^{3}$ mayoritas penduduk Sumatera Utara menganut agama Islam yakni 63,36\%, kemudian Kristen 33,99\%, Protestan 26,665, Katolik 7,33\%, Budha 2,43\%, Konghucu 0,11\%, Hindu 0,10\% dan Parmalim 0,01\%. Sarana peribadatan merupakan sarana mengisi kebutuhan rohani yang perlu disediakan,

1 Dukcapil.kemendagri, "'Visualisasi Data Kependuduakan - Kementerian Dalam Negeri 2020," Www.Dukcapil.Kemendagri.Go.Id., n.d. diakses 16 Oktober 2021.

${ }^{2}$ BPS Sumatera Utara, Sumatera Utara Dalam Angka 2021 (Medan: BPS Sumatera Utara, 2021).

${ }^{3}$ BPS Sumatera Utara, Sumatera Utara Dalam Angka 2021 (Medan: BPS Sumatera Utara, 2021). 
karena itu sarana rumah ibadah terdapat 12.499 gereja Protesan, 10.738 masjid, 4.822 mushola, 2.488 gereja Katolik, 393 Vihara, 99 Klenteng dan 84 Pura $^{4}$.

Berdasarkan gambaran singkat mengenai Provinsi Sumatera Utara di atas, tampak bahwa mayoritas penduduknya mendiami wilayah perkotaan dengan mayoritas pemeluk agama Islam dan berbaur dengan banyak non muslim. Hal ini tentunya menjadi peluang bagi civitas academica untuk melakukan pembinaan keislaman yang lebih intensif agar dapat menguatkan akidah, keistikamahan dan akhlak kaum muslimin, di samping sebagai bentuk pengamalan darma pengabdian kepada masyarakat. Namun, dikarenakan kondisi pandemi Covid-19 yang melanda dunia ini, tidak terkecuali Indonesia, juga berdampak pada perubahan perilaku masyarakat dalam beraktivitas sehari-hari, termasuk dalam kegiatan pendidikan yang berbasis virtual, dan kondisi ini disebut era new normal ${ }^{5}$.

Pada dasarnya berbagai bentuk kegiatan pengabdian masyarakat harus tetap diupayakan agar dapat berjalan dengan optimal, meskipun dengan berbagai penyesuaian terhadap perubahan yang terjadi di masa pandemi Covid-19. Salah satu alternatif yang dapat ditempuh adalah pelaksanaan kegiatan pengabdian masyarakat secara virtual ${ }^{6}$. Program Kuliah Kerja Nyata $(\mathrm{KKN})$ di perguruan tinggi termasuk kegiatan pendidikan sekaligus pengabdian kepada masyarakat yang mengalami penyesuaian selama masa pandemi Covid-19. Hal ini pula yang ditempuh oleh Sekolah Tinggi Ilmu Islam dan Bahasa Arab (STIBA) Makassar dalam pelaksanaan KKN Angkatan IV di Sumatera Utara, terutama kalangan mahasiswi, di mana jarak tidak lagi menjadi penghalang untuk tetap berkontribusi dalam pengabdian kepada masyarakat.

Atas alir naratif di atas, maka ditetapkan tujuan kegiatan KKN Angkatan IV STIBA Makassar di Sumatera Utara ini yaitu sebagai berikut: (1) Merupakan sarana dalam meningkatkan kepekaan sosial mahasiswi melalui dakwah yang dilandasi oleh ilmu syariat sebagai wujud nyata kontribusi pengabdian kepada masyarakat; (2) Membekali mahasiwi beragam skill dakwah lapangan sebagai aplikasi pengetahuan yang telah didapatkan dibangku perkuliahan; (3) Sebagai pengamalan tridarma perguruan tinggi, khusunya darma pengabdian kepada masyarakat.

Meskipun pelaksanaan KKN ini dilakukan secara virtual, namun secara implementatif tetap diawali dengan melakukan survei kondisi dan lapangan berbasis sosial media, kemudian dilakukan analisis masalah dengan menggunakan metode SOAR, sehingga dirumuskan narasi penjabarannya sebagai berikut: (1) Strenght: Mayoritas penduduk Sumatera Utara beragama Islam. Mahasiswi KKN STIBA telah dibekali dengan beberapa pelatihan pembinaan keagamaan seperti, pengajaran AlQur'an untuk dewasa, pengajaran bahasa Arab, public speaking dan kemampuan mengoperasikan aplikasi online; (2) Opportunities: Mayoritas penduduk Sumatera

4 Widiyanarti, Tantry. "Pengajian Al Quran sebagai Perekat Kebhinnekaan (Kajian Pola Komunikasi dalam Pengembangan Nilai-nilai Pancasila pada Masyarakat Multikultural melalui Pengajian Al Quran di Medan, Sumatera Utara)." Nyimak: Journal of Communication 1.1 (2017): 1-21.

5 Mukran H. Usman, Aswar, and Andi Wahyu Irawan, "Syariat Islam Dan Kemaslahatan Manusia Di Era New Normal Pada Kegiatan Keagamaan Dan Pendidikan," FENOMENA: Jurnal Penelitian 12, no. 1 (2020): 89-106, https://doi.org/http:// doi.org/10.21093/fj.v12i1.2456.

${ }^{6}$ Hijrayanti dkk "Taklim Virtual Muslimah Pada Masa Pandemi Covid-19 Di Wilayah Provinsi Bangka Belitung,” WAHATUL MUJTAMA’: Jurnal Pengabdian Masyarakat 2, no. 1 (2021): 102-15. 
Utara berdomisili di daerah perkotaan. Adanya jaringan internet yang memadai di wilayah perkotaan, kebutuhan muslimah akan pengajaran Al-Qur'an di masa pandemik; (3) Aspiration: Peningkatan pemahaman keislaman dengan lebih baik khususnya Muslimah di Sumatera Utara; (4) Result: Pemahaman agama muslimah Sumatera Utara semakin bertambah dimasa pandemi.

Berangkat dari analisis singkat di atas, maka ditetapkan beberapa program kerja yang relevan dan dinilai adaptif-progresif untuk diterapkan di Provinsi Sumatera Utara, seperti seminar Al-Qur'an, tahfiz Al-Quran harian, pengajaran Al-Qur'an pengajaran metode dirosa, taklim fikih muslimah, dan poster dakwah. Programprogram tersebut sebetulnya telah dilakukan oleh pelaksana pengabdian sebelumnya, namun sisi pembedanya adalah pada lokus pelaksanaannya, yakni di Provinsi Sumatera Utara. Aksi pengabdian kepada masyarakat $(\mathrm{PkM})$ telah diterapkan oleh sejumlah akademisi di Indonesia dengan memakai konsep KKN berbasis virtual, di antaranya: (1) PkM yang bertajuk, "Taklim Virtual Muslimah pada Masa Pandemi Covid-19 di Wilayah Provinsi Bangka Belitung," oleh Hijrayanti Sari dkk,. Tujuan kegiatan ini untuk menambah wawasan keislaman, fikih seputar muslimah, dan tentunya berorientasi pada upaya meningkatkan iman dan takwa para muslimah ${ }^{7}$; (2) PkM dengan tema, "Program Belajar Islam Intensif bagi Muslimah di Desa Kenari, Kabupaten Pohuwato, Gorontalo," oleh Asnawati Patuti, dkk. Kegiatan ini bertujuan untuk menghidupkan nilai-nilai Al-Qur'an bagi masyarakat Desa Kenari secara umum dan muslimah secara khusus melalui program-program KKN seperti pembelajaran tahsin dan tajwid"; (3) PkM yang mengusung tema, "Pembelajaran Metode Dirosa di Desa Majannang Kabupaten Gowa," oleh Hendra Wijaya, dkk. Pengabdian ini bertujuan memberantas buta huruf Al-Qur'an di Desa Majannang dengan menggunakan metode belajar Al-Quran untuk orang dewasa atau Dirosa9; (4) PkM dengan tema, "Peranan Kuliah Kerja Nyata sebagai Wujud Pengabdian Kepada Masyarakat di Tengah Pandemi Covid-19", oleh Ahmad Ulil Albab. Tujuan dari pengabdian ini adalah untuk mengembangkan potensi mahasiswa dengan tetap melaksanakan program KKN baik secara langsung di lapangan maupun secara daring, dengan demikian masyarakat tetap dapat merasakan manfaat KKN di tengah masa pandemi Covid- $19^{10}$.

Beberapa hasil PkM yang telah dipaparkan di atas menunjukkan bahwa pengajaran Al-Quran untuk muslimah telah banyak dilaksanakan sebelumnya, baik melalui pelaksanaan program secara langsung di lokasi KKN maupun secara virtual. Namun, yang menjadi perbedaan pada KKN IV Virtual STIBA Makasar ini adalah program kegiatan yang lebih terfokus pada pembinaan dan pengajaran Al-Qur'an yang

${ }^{7}$ Hijrayanti dkk "Taklim Virtual Muslimah Pada Masa Pandemi Covid-19 Di Wilayah Provinsi Bangka Belitung," WAHATUL MUJTAMA’: Jurnal Pengabdian Masyarakat 2, no. 1 (2021): 102-15.

${ }^{8}$ et al Patuti, Asnawati, "Program Belajar Islam Intensif Bagi Muslimah Di Desa Kenari, Kabupaten Pohuwato, Gorontalo," WAHATUL MUJTAMA': Jurnal Pengabdian Masyarakat 2, no. 1 (2021): 70-82.

9 Wijaya, Hendra, dkk "Pembelajaran Metode Dirosa Di Desa Majannang Kabupaten Gowa," WAHATUL MUJTAMA’: Jurnal Pengabdian Masyarakat 1, no. 1 (2020): 67-74.

${ }^{10}$ Ulil Albab and AL Umar Ahmad, "Peranan Kuliah Kerja Nyata Sebagai Wujud Pengabdian Kepada Masyarakat Di Tengah Pandemi Covid-19 (Studi Kasus IAIN Salatiga KKN 2021)," E-Amal: Jurnal Pengabdian Kepada Masyarakat 1, no. 1 (2021): 39-50. 
dilakukan secara virtual melalui aplikasi meeting (Zoom dan Google meet). Selain itu, lokus pengabdian masyarakatnya difokuskan kepada masyarakat Sumatera Utara, sehingga masa pandemi Covid-19 dan jarak yang terbilang jauh dari STIBA Makassar tidak menjadi penghalang pelaksanaan program pengabdian kepada masyarakat.

\section{PEMBAHASAN}

\section{Seminar Al-Quran Virtual (Webinar)}

Seminar Al-Qur'an yang dilaksanakan secara virtual via aplikasi Zoom meeting merupakan salah satu program kerja yang dilakukan guna mengajak para muslimah Nusantara khususnya Provinsi Sumatera Utara untuk memahami akan pentingnya menjadikan Al-Qur'an sebagai pedoman hidup. Selain itu, tujuan dari program ini adalah memberikan semangat dalam mempelajari dan mengamalkan Al-Qur'an dalam kehidupan sehari-hari. Seturut dengannya, Maya mengatakan bahwa Al-Qur'an sebagai pedoman hidup akan lebih afdal jika ditadabburi untuk mendapat hikmah yang agung ${ }^{11}$. Adapun kegiatan ini ditargetkan dihadiri oleh 100 orang peserta muslimah.

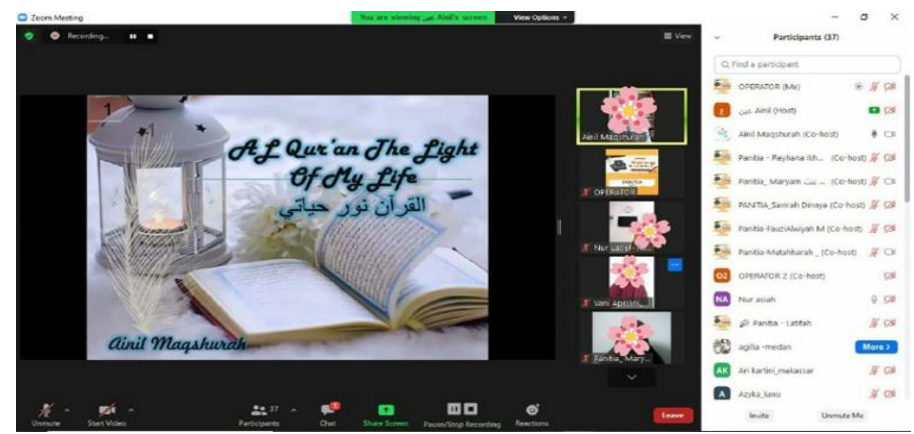

Gambar 1. Seminar Al-Quran Virtual

Namun, dalam pelaksanaannya hanya dihadiri oleh 26 orang peserta dari 51 orang yang telah melakukan pendaftaran. Adapun tema atau judul diusung dalam seminar ini adalah, "Al-Quran Pedoman Hidupku”. Pada seminar ini, pemateri yang memaparkan kajian adalah ustazah Ainil Maqsurah, S.H., ia merupakan seorang dosen Sekolah Tinggi Ilmu Islam dan Bahasa Arab (STIBA) Makassar. Terakhir, follow-up dari kegiatan seminar ini yakni terbentuknya 5 kelompok belajar Al-Qur'an metode Dirosa dan kelompok belajar Islam intensif.

\section{Tahfiz Al-Qur'an Harian (Program 10 Hari)}

Kegiatan ini merupakan bentuk follow-up dari seminar Al-Qur'an sebelumnya. Program ini dibuka khusus untuk muslimah yang ingin menghafal Al-Qur'an.

11 Maya, Abu Aisyah Rahendra. "Perspektif Al-Qur 'an Tentang konsep Al-Tadabbur." AlTadabbur: Jurnal Ilmu Al-Qur'an dan Tafsir 1.01 (2017). 


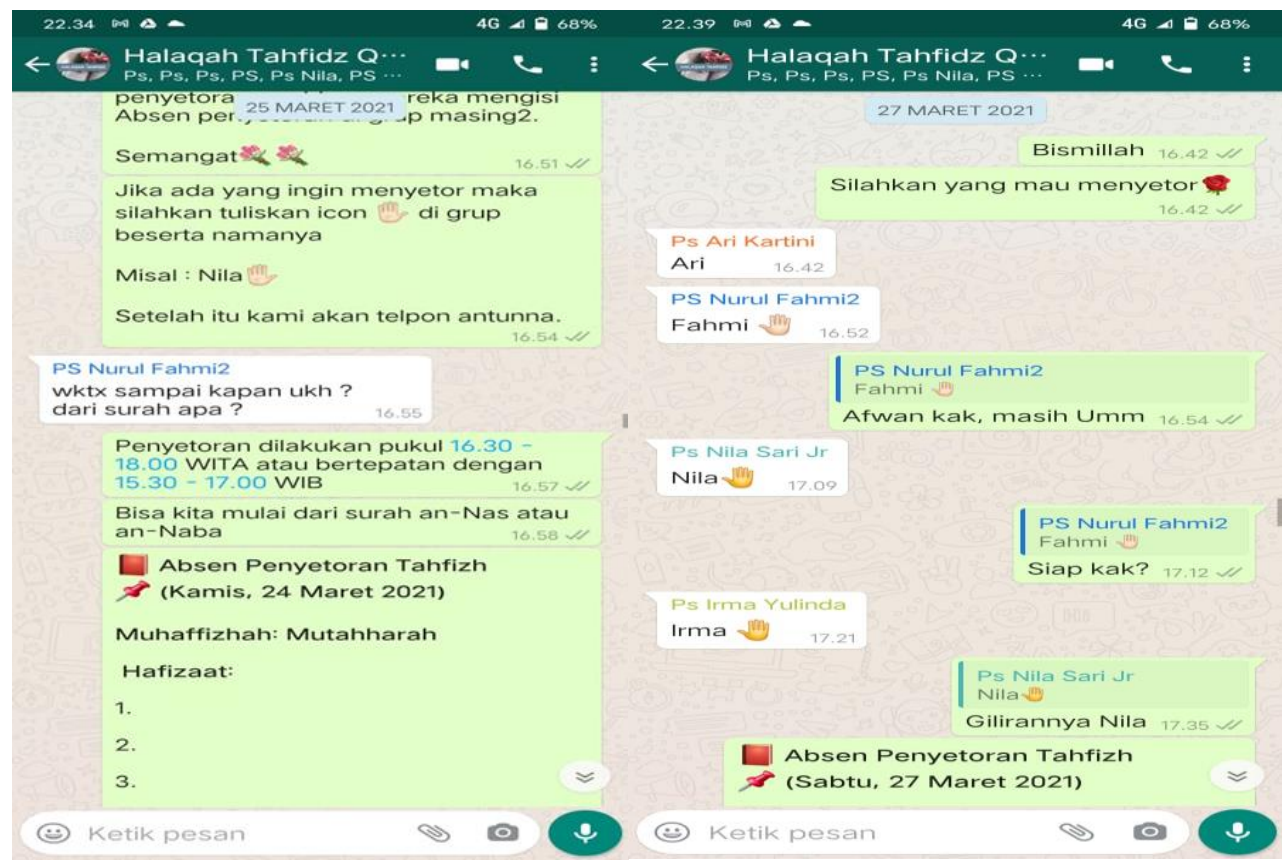

Gambar 2. Kegiatan Menghafal Al-Quran Harian

Tujuan program ini di antaranya adalah menambah kedekatan muslimah kepada AlQur'an untuk menjadi hāmilātul Qur'an (pembawa Qur'an), serta sebagai sarana menambah hafalan ayat Al-Qur'an sekaligus perbaikan bacaan atau hafalan yang keliru $^{12}$. Sehubungan dengannya, Aflisia mengatakan bahwa menjadi seorang hafizah tidaklah mudah, paling tidak ia mesti memiliki niat yang ikhlas, tekad yang kuat, menjauhi maksiat, dan memperbanyak doa ${ }^{13}$.

Kegiatan ini dilaksanakan selama 10 hari via aplikasi Whatsapp dan diikuti oleh 22 orang peserta, di mana proses kegiatan penyetoran hafalan dilakukan oleh peserta tahfizh kepada muhaffizhahnya masing-masing di tiap halaqah atau kelompok. Waktu penyetoran hafalan cukup fleksibel yang sesuai kesepakatan antara muhaffizah (guru hafizah) dan anggota kelompok. Bagi peserta yang belum mampu menghafalkan dengan baik dan lancar surah atau ayat-ayat yang disetorkan, maka akan dibimbing lebih lanjut untuk dapat membaca dan menghafal sesuai dengan kaidah-kaidah ilmu tajwid.

\section{Pengajaran Al-Quran Metode Dirosa}

Program ini dilaksanakan secara virtual bagi para muslimah di Sumatra Utara yang notabanenya kurang mampu membaca Al-Qur'an dengan baik, atau bahkan buta huruf hijaiah ataupun belum mampu membaca Al-Quran sesuai kaidah tajwid. Tujuan program pembinaan Dirosa ini antara lain: (1) Untuk meningkatkan semangat

${ }^{12}$ Rachmat bin Badani Tempo, Ahmad Syaripudin, and Irsyad RAFI, "Pembinaan Masyarakat Qur'ani Di Kecamatan Manggala Melalui Kkn Stiba Makassar," Wahatul Mujtama' Jurnal Pengabdian Masyarakat Sekolah Tinggi ILmu Islam Dan Bahasa Arab (STIBA) Vol. 2, no. No. 1 (2021), https://doi.org/https://journal.stiba.ac.id/index.php/wahatul/article/view/340/205.

13 Aflisia, Noza. "Urgensi bahasa Arab bagi hafizh Al-Qur'an." FOKUS Jurnal Kajian Keislaman dan Kemasyarakatan 1.1 (2016): 47-66. 
seseorang dalam mempelajari dan mengajarkan Al-Qur'an; (2) Memberikan tambahan wawasan dasar-dasar keislaman kepada peserta Dirosa; dan (3) Untuk memberikan pembelajaran baca Al-Qur'an kepada remaja dan orang dewasa agar dapat membaca sesuai ilmu dan kaidah tajwid ${ }^{14}$.

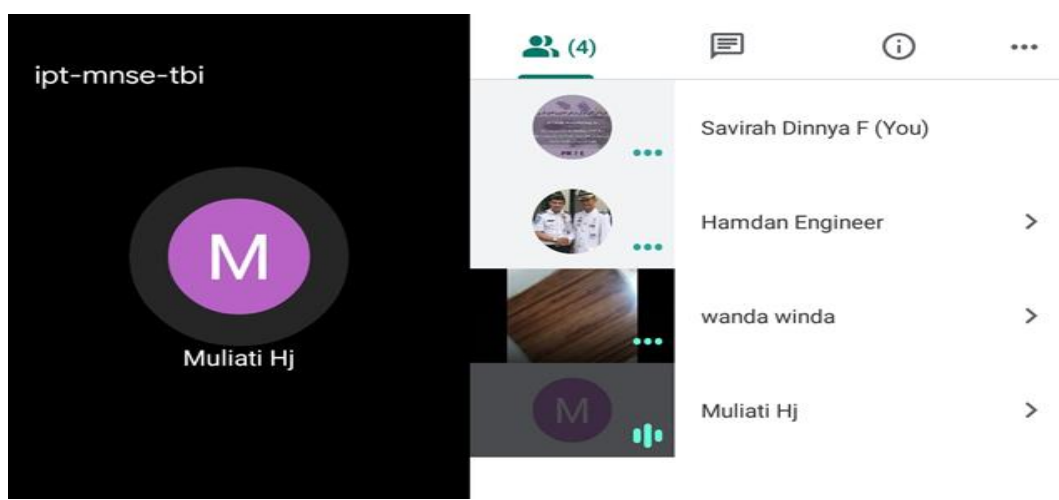

Gambar 3. Pembelajaran Online Metode Dirosa

Metode Dirosa merupakan cara belajar Al-Qur'an yang dilakukan secara klasikal dengan jadwal pembelajaran sekali tiap pekan via aplikasi Google meet dengan durasi 2 jam pembelajaran, yang terdiri dari penyampaian materi dan praktek langsung dengan durasi 1 jam 40 menit dan 20 menit materi Belajar Islam Intensif. Kegiatan ini diikuti oleh 13 orang peserta dari Sumatra dan Medan yang dibagi menjadi 2 kelompok.

\section{Taklim Fikih Muslimah}

Program ini merupakan persembahan khusus untuk muslimah berkaitan permasalahan fikih seputar wanita. Secara umum taklim muslimah bertujuan untuk menambah wawasan keislaman ${ }^{15}$ serta pemahaman yang benar terkait permasalahan fikih yang sering dialami para muslimah. Materi pilihan yang disajikan di antaranya: fikih darah kebiasaan wanita, fikih wudu, salat, dan puasa. Kegiatan ini diselenggarakan via aplikasi Zoom meeting dan dihadiri oleh muslimah dari Sumatera Utara dan berbagai wilayah lainnya. Acara tersebut dimulai dengan pembukaan oleh moderator, lalu pemaparan materi fikih disampaikan oleh ustadzah Reyhana Ikhwan, dan dilanjutkan dengan sesi tanya jawab, kemudian penutup. Program ini terlaksana sebanyak empat kali dengan jumlah peserta berkisar di atas sepuluh orang.

${ }^{14}$ Wijaya, Hendra, dkk "Pembelajaran Metode Dirosa Di Desa Majannang Kabupaten Gowa," WAHATUL MUJTAMA': Jurnal Pengabdian Masyarakat 1, no. 1 (2020): 67-74.

${ }^{15}$ Eka Syahriani and Rifai Awal, "Upaya Meningkatkan Pemahaman Keagamaan Masyarakat Melalui Program Pendidikan Dan Sosial Keagamaan Di Desa Alatengae Kabupaten Maros," WAHATUL MUJTAMA': Jurnal Pengabdian Masyarakat 1, no. 2 (2020): 142-56. 


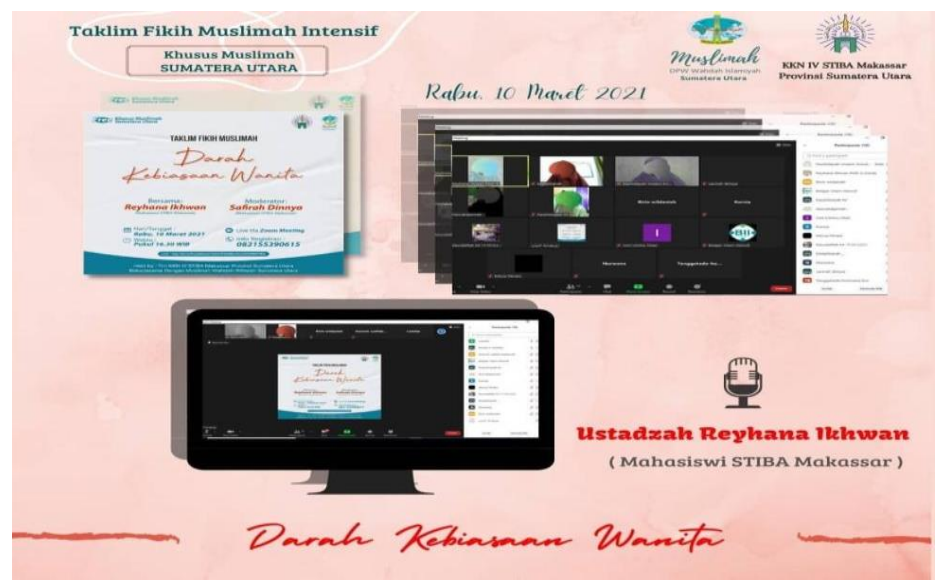

Gambar 4. Taklim Fikih Muslimah

Pelaksanaan program ini secara virtual tentu berbeda dengan pelaksanaanya secara langsung dilapangan seperti yang dilakukan mahasiswi KKN Kemanusian Sekolah Tinggi Ilmu Islam dan Bahasa Arab (STIBA) Makassar di Kecamatan Malunda ${ }^{16}$, di mana kestabilan layanan jaringan internet cukup mempengaruhi kelancaran kegiatan. Namun demikian, program ini mendapat respon positif dari peserta, yang terlihat dari komitmen kehadiran peserta setiap pekannya untuk menyimak materi fikih yang disajikan.

\section{Poster Dakwah}

Poster dakwah merupakan agenda harian TIM KKN untuk menyebarkan dakwah via social media seperti Facebook, Instagram, Whatsapp, dan Telegram yang dapat memberikan nasehat ataupun wawasan Islami kepada para pengguna social media yang membacanya. Tujuan program ini yaitu menyebarluaskan ayat Al-Qur'an dan hadis Nabi Muhammad saw. serta untaian mutiara nasehat para ulama kepada para pengguna social media, terkhusus muslimah Sumatera Utara.

16 Zulfiah Sam and Saadal Jannah, "Pelaksanaan KKN Kemanusiaan Mahasiswi STIBA Makassar Di Kelurahan Malunda Kabupaten Majene," WAHATUL MUJTAMA': Jurnal Pengabdian Masyarakat 2, no. 1 (2021): 1-10. 

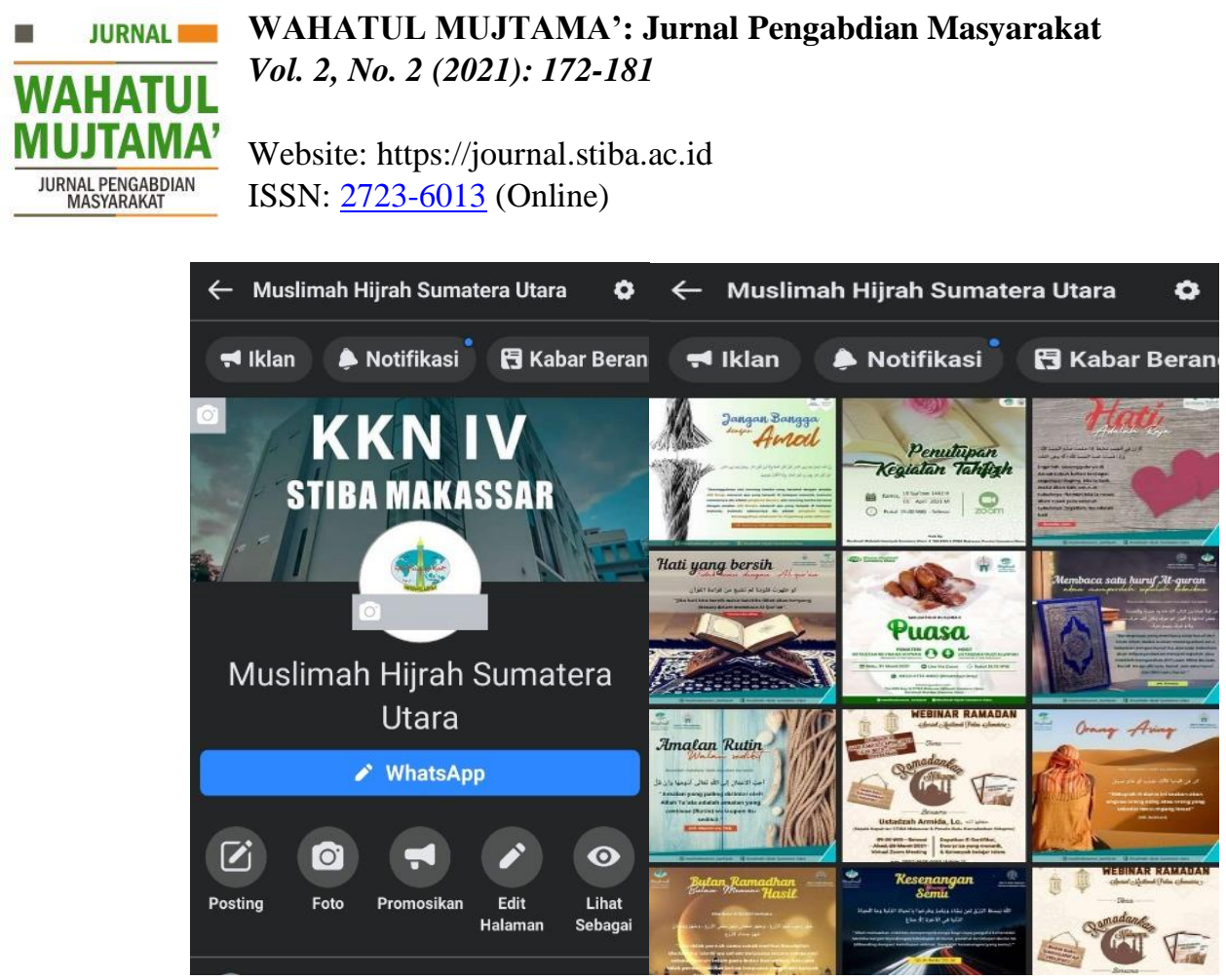

Gambar 5. Poster Dakwah

Sehubungan dengan di atas, beberapa hasil penelitian menunjukkan bahwa poster dakwah yang memanfaatkan media sosial cukup berpengaruh dalam menyampaikan pesan dakwah secara kreatif dan inovatif ${ }^{17}$ dan meningkatkan minat mad' $^{\prime} u^{18}$. Program ini berlangsung setiap hari selama masa $\mathrm{KKN}$ dan mendapatkan sambutan yang baik dari pengguna social media.

\section{KESIMPULAN}

Kondisi pandemi Covid-19 yang melanda dunia tidak menyurutkan semangat pengabdian kepada masyarakat oleh mahasiswi Kuliah Kerja Nyata (KKN) Sekolah Tinggi Ilmu Islam dan Bahasa Arab (STIBA) Makassar angkatan IV sebagai wujud pengamalan Tri Dharma Perguruan Tinggi. Berbagai program yang berhasil dilaksanakan secara virtual antara lain, seminar Al-Qur'an, tahfiz harian, pengajaran Al-Quran metode Dirosa, taklim fikih muslimah dan poster dakwah. Berbagai kendala yang dihadapi selama masa KKN virtual ini memberikan banyak pengalaman bagi para mahasiswi dalam menyajikan dakwah Islam kepada masyarakat khususnya para muslimah. Sambutan yang baik atas pelaksanaan KKN ini terlihat dari tetap berjalannya berbagai kegiatan pembinaan berbasis Al-Quran meskipun masa KKN telah berakhir.

\section{DAFTAR PUSTAKA}

Aflisia, Noza. "Urgensi bahasa Arab bagi hafizh Al-Qur'an." FOKUS Jurnal Kajian Keislaman dan Kemasyarakatan 1.1 (2016): 47-66.

Albab, Ulil, and AL Umar Ahmad. "Peranan Kuliah Kerja Nyata Sebagai Wujud Pengabdian Kepada Masyarakat Di Tengah Pandemi Covid-19 (Studi Kasus IAIN Salatiga KKN

17 Wibowo, Ari. "Digitalisasi Dakwah di Media Sosial Berbasis Desain Komunikasi Visual." Jurnal Bimbingan Penyuluhan Islam 2.02 (2020): 179.

${ }^{18}$ Hidayat, Ahmad Arief, Bambang S. Ma'arief, and Nandang HMZ. "Pengaruh Poster Dakwah Islam pada Akun Sosial Media Instagram@ Masjid_Habiburrahman Terhadap Minat Mad'u di Kota Bandung." (2019). 
2021)." E-Amal: Jurnal Pengabdian Kepada Masyarakat 1, no. 1 (2021): 39-50.

Dukcapil.kemendagri. "'Visualisasi Data Kependuduakan - Kementerian Dalam Negeri 2020." www.dukcapil.kemendagri.go.id., n.d.

Hidayat, Ahmad Arief, Bambang S. Ma'arief, and Nandang HMZ. "Pengaruh Poster Dakwah Islam pada Akun Sosial Media Instagram@ Masjid_Habiburrahman Terhadap Minat Mad'u di Kota Bandung." (2019).

Maya, Abu Aisyah Rahendra. "Perspektif Al-Qur 'an Tentang konsep Al-Tadabbur." AlTadabbur: Jurnal Ilmu Al-Qur'an dan Tafsir 1.01 (2017).

Patuti, Asnawati, et al. "Program Belajar Islam Intensif Bagi Muslimah Di Desa Kenari, Kabupaten Pohuwato, Gorontalo." WAHATUL MUJTAMA': Jurnal Pengabdian Masyarakat 2, no. 1 (2021): 70-82.

Putri, Sri Ujiana, and Dewi Indriani. "Safari Dakwah Berbasis Islam Mahasiswi KKN STIBA Makassar Di Dusun Dasan Bagik, Lombok Timur." WAHATUL MUJTAMA': Jurnal Pengabdian Masyarakat 2, no. 1 (2021): 11-20.

Sam, Zulfiah, and Saadal Jannah. "Pelaksanaan KKN Kemanusiaan Mahasiswi STIBA Makassar Di Kelurahan Malunda Kabupaten Majene." WAHATUL MUJTAMA': Jurnal Pengabdian Masyarakat 2, no. 1 (2021): 1-10.

Sari, Hijrayanti, et al. "Taklim Virtual Muslimah Pada Masa Pandemi Covid-19 Di Wilayah Provinsi Bangka Belitung." WAHATUL MUJTAMA': Jurnal Pengabdian Masyarakat 2, no. 1 (2021): 102-15.

Syahriani, Eka, and Rifai Awal. "Upaya Meningkatkan Pemahaman Keagamaan Masyarakat Melalui Program Pendidikan Dan Sosial Keagamaan Di Desa Alatengae Kabupaten Maros." WAHATUL MUJTAMA': Jurnal Pengabdian Masyarakat 1, no. 2 (2020): 14256.

Tempo, Rachmat bin Badani, Ahmad Syaripudin, and Irsyad RAFI. "Pembinaan Masyarakat Qur'ani Di Kecamatan Manggala Melalui KKN STIBA Makassar." Wahatul Mujtama" Jurnal Pengabdian Masyarakat Sekolah Tinggi ILmu Islam Dan Bahasa Arab (STIBA) Vol. 2, no. $\quad$ No. 121 (2021). https://doi.org/https://journal.stiba.ac.id/index.php/wahatul/article/view/340/205.

Usman, Mukran H., Aswar, and Andi Wahyu Irawan. "Syariat Islam Dan Kemaslahatan Manusia Di Era New Normal Pada Kegiatan Keagamaan Dan Pendidikan." FENOMENA: Jurnal Penelitian 12, no. 1 (2020): 89-106. https://doi.org/http:// doi.org/10.21093/fj.v12i1.2456.

Utara, BPS Sumatera. Sumatera Utara Dalam Angka 2021. Medan: BPS Sumatera Utara, 2021.

Wibowo, Ari. "Digitalisasi Dakwah di Media Sosial Berbasis Desain Komunikasi Visual." Jurnal Bimbingan Penyuluhan Islam 2.02 (2020): 179.

Widiyanarti, Tantry. "Pengajian Al Quran sebagai Perekat Kebhinnekaan (Kajian Pola Komunikasi dalam Pengembangan Nilai-nilai Pancasila pada Masyarakat Multikultural melalui Pengajian Al Quran di Medan, Sumatera Utara)." Nyimak: Journal of Communication 1.1 (2017): 1-21.

Wijaya, Hendra, et al. "Pembelajaran Metode Dirosa Di Desa Majannang Kabupaten Gowa." WAHATUL MUJTAMA': Jurnal Pengabdian Masyarakat 1, no. 1 (2020): 67-74. 